\title{
Minas Gerais
}

National Cancer Institute

\section{Source}

National Cancer Institute. Minas Gerais. NCI Thesaurus. Code C156325.

A state in the Southeast Region of Brazil. Its capital is Belo Horizonte. 